\title{
Útero, psiquis y climaterio: un acercamiento desde la endocrinología antropológica
}

\author{
Elvira M. MELIÁN \\ Hospital Universitario La Paz \\ emelian@telefonica.net
}

Recibido: Noviembre 2014

Aceptado: Octubre 2015

\begin{abstract}
RESUMEN:
Como medida del tiempo, el ciclo gonadal femenino se ha ligado ancestralmente a atributos de inestabilidad y mutabilidad vinculados al ci clo lunar. Sobre esta sup erstición sedimentará la contemplación de 1 a menstruación como impura $\mathrm{y}$, en Occidente, como maligna, tras la sexualización del pecado en la religi ón cristiana. En este contexto, y hasta el inicio del conocimiento de la fisiología del climaterio, el cese de la fertilidad y los cambios fenotípicos secundarios al apagamiento ovárico han propiciado un discurso basado en una visión mágica y creencial de la mujer menopaúsica como ser desequilibrado, enajenado y dañino. Las interpretaciones de este perfil psíquico a lo largo de la historia -profetas, místicas, hechicerasse transmutarán en las histéricas, depresivas ol ábiles emocionales contemporáneas, evidenciando el peso de ancestrales creencias cósmicas y mitológicas sobre el subc onsciente colectivo. Un peso que, junto a 1 os condicionantes culturales, sociológicos y biológicos actuales, aún hoy modula las categorías nosológicas de la medicina.
\end{abstract}

Palabras claves: Endocrinología antropológica, Menopausia, Melancolía, Histeria, Útero, Hechicería.

\section{Útero, Psiquis and climatery: an approach since the anthropological endocrinology}

\begin{abstract}
The female gonadal cycle has been ancestrally linked to traits of an em otional and mutable mood, partly attributed to moon phases. This would pave the way along centuries to consider menstruation as something impure and, in the western civilization, even evil (note sexualization of sin in Christian culture). In this context and until the pathophysiology of menopause was approached with a scien tific perspective, cessation of fertility an d phenotypic changes associated with ova rian quenching have fostered a magical and prejudicial vision a s a state related to disequilibrium, lunacy or harm. Historical portraits of women with this psychological profile through time as prophets, mystic, witches have turned in today's hysterical, depressive or emotionally labile diagnoses. This fact reveals the impact of long standing beliefs based on myths and cosmic phenomena on the contemporary collective subconscious. An impact that, in conjunction with cultural, social and biological issues, even today, modulate the medical nosological categories.
\end{abstract}

Key words: Anthropological endocrinology, Menopause, Melancholy, Hysteria, Utero, witchcraft. 


\section{INTRODUCCIÓN}

"El miembro que más asido está de las alteraciones del útero es el cerebro (...), por donde se entiende que el úter o y sus testículos son de grande eficacia para comunicar a todas las de más partes del cue rpo su temperamento, mayormente al cerebro, por ser frío y húmedo como ellos. Y si nos acordamos que la frialdad y humedad son las calidades que echan a perder la parte emocional" (Huarte de San Juan, 1953: 493).

Podemos acercarnos a la im pronta de la cultura sobre las categorías nosológic as de la medicina bajo dos perspectivas temporales: vigente o histórica (Martínez, 2011). Ejemplos actuales de la dinámica entre sociedad y salud son el aumento de pre valencia de obesidad y diabetes del adulto secundario a hábitos dietéticos (Zafon, 201 1), o las categorías diagnosticas en psiquiatría. Así, en las progresivas ediciones del $\mathrm{DSM}^{1}$ encontramos: 1) designaciones nuevas para trastornos de clínica equivalente -caso de la depresión para lo que ant es era melancolía-, 2) i néditas categorías diagnósticas que medicalizan situaciones desagradable $\mathrm{s}$ de la vida cotidiana -caso del síndrome de ansiedad social- y 3) fiscalización de pro cesos naturales (Aho, 2008: 136). Paradigma de este últi mo caso es la vida gonada 1 femenina, víctima de la transfor mación del síndrome premenstrual en "desorden di strófico de la fa se luteal tardía", de la anorgasmia -en su día una virtud- en "desorden de disfunción sexual fem enino"; o de un enfoque intervencionista tanto de la infe rtilidad -una carencia que precisa técnicas de reproducción asistida- co mo del $\mathrm{n}$ acimiento -un proceso inducido, ligado a un ingente número de cesáreas- (Aho, 2008:76).

La otra pers pectiva deviene del anál isis de la ti pificación secular de cier tas entidades en un "continuo", culturalmente dependiente, desde pecado $/ \mathrm{m}$ agia a vicio/crimen, para terminar en patología o disolución del diagnóstico (Bynum, 2001a, $2001,2002$ y 2003 $)^{2}$. Desde esta perspectiva histórica también el ciclo sexual femenino se nos aparece como un arquetipo bio-psico-socio-cultural privilegiado para analizar la connivencia ancestral entre biología y cultura (Judd, 2012). Acotando el cam po al climaterio, a lo largo de los siglos hemos asistido al progresivo tránsito de la climatérica desde hechicera primitiva a bruja -acédica y/o poseída- de la Inquisición, desde ahí a la melancólic a/histérica del psicoanálisis del XIX, y, posteriormente, a la "depleccionada estrogénica" necesit ada de sustitución horm onal del pasado siglo (Melián, 2011). Debem os esta singularidad a la pr oyección atávica de sim bolismos psíquicos sobre fenómenos fisioló gicos como el nacim iento, menstruación, concepción, embarazo, sexualidad, o climaterio, que modulan su "realidad bi ológica" (Newman, 2009:279). En el ori gen de este fenómeno cohabi tan, por un lado la

\footnotetext{
${ }^{1}$ Manual Diagnóstico y Estadístico de Trastornos Mentales.

${ }^{2}$ Ejemplos de pecados capitales reconvertidos en enfermedades modernas, además del desorden depresivo para la acedia, son el desorden de adicción sexual para la lujuria, el desorden obsesivo compulsivo para la avaricia, el desorden de a buso de substancias para la gula, el desorden intermitente explosivo. para la ira, el desorden de ansiedad social para la envidia o el de personalidad narcisista para la soberbia (Aho, 2008:67)
} 
condición universal de "medida del tiem po" del ciclo fem enino y, por otro, la identificación de las funci ones reproductivas con un $\mathrm{m}$ undo ancestral donde el bajo vientre encierra el alma, y las labores de nutrición y procreación aparecen envueltas en una sospechosa animalidad ligada simbólicamente a sinrazón y desequilibrio (André, 2008: 150).

La intersección entre "un por qué creenci al y un cómo empírico" (Martínez, 2011:25) justifica la recurrente asociación entre útero y perturbación mental a lo largo de los siglos. Las palab ras de Huar te de San Juan que intr oducen este texto materializan una corriente de pensam iento que alcanzará su cenit durante la primera mitad del si glo XX, con las teorías psicoanalíticas de Freud y la endocri nología psicosomática alemana (Meng, 1920). Los más significativos representantes de es ta última corriente, pese a no encontrar "ni nguna variación hormonal responsable de alteraciones psíquicas específicas, ni ningún ins tinto o hum or primariamente determinado por un acontecer hormonal", proclamaban la "posibilidad de condicionamiento secundario entre suc eso hormonal y humor/instinto y viceversa" (Meng, 1920: 423). Es decir, para la psic o-endocrinología "el efecto psíquico de una hormona y de su suceso endocrino depe nde ampliamente de la constitución, disposición, situación, personalidad y estadio de desarrollo de la persona" (Meng, 1920: 423). Tal es la vigencia del mito aplicado a la menopausia, que en nuestros días se sigue debatiendo la hipótesis de que las fluctuaciones hormonales ligadas al cese de la función ovárica favorecen la inestab ilidad emocional (Ayers y cols, 2010) ${ }^{3}$. Y, aunque hoy no se consi dera un proceso patológico ni necesitado de sus titución hormonal, la menopausia se sigue defini endo como un "estado de hipersensibilidad a estímulos externos" (Freeman, 2010), definición celosamente parecida a la que se aplica a la melancolía: "estado de hi persensibilidad" (Galindo, 2005) o "sensación de pérdida sin objeto" (Freud, 1917:4; Sullivan, 2008:884). De hecho la literatura médica actual encierra interminables meta-análisis a favo $\mathrm{r}$ (Llaneza y cols, 2011; Weber, 2014), o en contra de la existencia de un desorden anímico o depresivo específico asociado con la menopausia (Bromberger, 2011) ${ }^{4}$.

Este artículo cul mina una serie de tra bajos dedicados a analiza $r$ la ancestral y bidireccional cooperación entre los c ambios hormonales y fenotípicos li gados al climaterio y el advenimiento de arquetipos simbólico femeninos, nega tivos andrógino/bruja- (Melián, 2011) o positivos -mística- (Melián, 2013a). Desde la perspectiva de la endocrinología antropológica retrocederemos hacia los orígenes de un acervo del subconsciente colectivo, el desequilibrio fem enino ligado al apagamiento del eje gonadal que, con una mínima capacidad de observación, aún encon tramos, maquillado pero latente, en nuestra sociedad contemporánea.

\footnotetext{
${ }^{3}$ El síndrome de disforia premenstrual o la depresión posparto son otros ejemplos.

${ }^{4}$ Depresión que, por cierto, representa, junto con el Desord en de Personalidad Múltiple, una nueva categoría diagnóstica englobando síntomas equiparables a la h isteria psicoanalítica del siglo XIX (Aho, 2008).
} 


\section{LO CREENCIAL. LA LUNA Y SUS ATRIBUTOS: MEDIDA DEL TIEMPO, CAUSA DEL CICLO MENSTRUAL Y SÍMBOLO DE MUTABILIDAD E INESTABILIDAD}

Desde que el humano tomó conciencia de su propia temporalidad las fases lunares se establecieron ubicuamente como primera epifanía dramática del tiempo y del eterno retorno (Durand, 2005:105). Para los pueblos primitivos esta luna era causa y medida del tiempo -por tanto del destino y de la propia mortalidad-, y del ciclo menstrual femenino (Durand, 2 005: 285) ${ }^{5}$. De ahí la raíz m on/men ligada a la palabra menstruación en num erosas lenguas indoeuro peas ${ }^{6}$. En esta relación arquetípica la menstruación, primer signo correlativo hum ano del ciclo lunar, aparece co mo reloj biológico fundamental ${ }^{7}$ (Iglesias Benavides, 2009:279). En un complejo simbolismo antropológico, a lo largo de los tiem pos la encontram os ligada a supersticiones genésicas, tóxicas y mágicas, al control de enfermedades específicas, e incluso de la meteorología, en lo que serán manifestaciones de su carácter sagrado (IglesiasBenavides, 2009). Desafortunadamente para la mujer, esta misma luna fue considerada desde muy temprano origen de los poderes mágicos y raíz de las enfermedades mentales, manifestadas en determinados momentos del ciclo lun ar (Briffault, 195 9: 288). Tan tarde como en el siglo XIX bajo la ley británica, el Acta de Locura definía como lunático al "demente con intervalos lúcidos dura nte las primeras dos fases de $1 \mathrm{a}$ luna y que era afligida por un period o de pérdida del entendimiento en el periodo posterior a la luna llena" (Eissler, 1946:145).

En la mujer, fuertemente influenciada por ese astro según Aristóteles y Galeno, la fase menstrual condicionará el desarrol lo de alteraciones físicas y psíquicas (IglesiasBenavides, 2009) ${ }^{8}$. El discurso de inestabilidad em ocional ligada al ciclo m enstrual sobrepasa los lím ites del climaterio y tiene sus raíces en la identificación de la naturaleza lunar, inestable y volátil (mudable), con lo femenino, en oposición al astro rey (Cirlot, 1969:291) ${ }^{9}$. En épocas donde religión y magia eran indistinguibles, los arquetipos femeninos de "luná tico, melancólico, loco" se encarn aron en hechiceras, brujas, místicas o profetas. Posteri ormente aparecerán las histéricas, lábiles emocionales, o depresiva s de la medicina pre-científica y científica ${ }^{10}$. Con similar criterio serán juzgadas de forma cultura lmente-dependiente manifestaciones derivadas de la "enfermedad del espíritu" tales como convulsiones, epilepsia, desvaríos, trances,

\footnotetext{
${ }^{5}$ El libro de Gilbert Duran, Las estructuras antropológicas de lo imaginario, analiza en profundidad el origen de los misterios instintivos, originales y de transformación espiritual. Sobre estos símbolos nictomorfos (luna, sangre menstrual, agua negra) consultar capítulo 2:94.

${ }^{6}$ Men, menós es luna en griego; la palabra latina es mensis, origen de menstruación.

${ }^{7}$ Junto a las aguas, otro de los elementos regulados por la luna.

${ }^{8}$ En pleno siglo XX Schick, médico, postuló la teoría de las "menotoxinas bacterianas" de la sangre menstrual y Montagu, antropólogo, atribuyó a los componentes químicos de la sangre menstrual capacidad de modificar vegetales o vino. Consultar Iglesias-Benavides, 2009:282.

9 Recordamos que Jesús curaba lunáticos cuya traducción posterior será epilépticos, la enfermedad sagrada.

${ }^{10}$ En el varón en hechiceros, profetas, curas, perturbados o genios.
} 
sonambulismo, crisis histéricas, o locura (Briffault, 1959: 298).

Conforme la connotación positiva de la feminidad y la madre tierra de las culturas no androcéntricas sufre un proceso de inversión de valores, la Gran Madre originaria deriva hacia arquetipos predominante, aunque no exclusivamente negativos (Durand, 2005:392). Esta evolución es atribuible al desarrollo de sociedades androcéntricas, en las que la conciencia de la propia mortalidad va ligada a la demonización de la menstruación y de la feminidad como símbolos de caducidad,

"En ciertas culturas se reemplazaron el conocimiento de la muerte y la toma de conciencia de la angustia temporal, como catástrofe fundamental, por el problema más anodino del bien y el mal, sexualizándolos en una época relativamente reciente bajo la ascética de una corriente ascética pesimista originada en la India extendida por todo cercano oriente hasta occidente, manifestada en el orfism o, escritos milesianos y platonism o, heredada por la Iglesia a través de San Agustín la fobia sexual d e gnósticos y maniqueos" (Durand,2005:119).

En este contexto, la identificación cristiana útero-pecado es una derivación religiosa de la ubicua, previa y profana consideración de la sangre menstrual como impura (Frazer, 1951). Ya en la prehistoria la menstruación era temida por favorecer el ataque animal a los cazadores (We ideger, 1976) y su carácter i mpuro está documentado en el mundo persa (800 A.C), indio (600 A.C), el Levítico (II A.C) o el Talmud judío (IV D.C). En su famosa Historia Natural, Plinio el Viejo (23-79 D.C), se explayaba sobre su monstruoso poder, cuya potenciación con el ciclo lunar convertía en fatal para el varón la relación con mujer menstruante durante la luna llena. Para este autor y para Aristóteles la m ujer era un varón mutilado, definiendo Galeno la sangre menstrual como resultado de la incapacida d del sexo femenino, frio y húmedo, para realizar de forma completa la cuarta co cción ${ }^{11}$, realizada en los testículos (Ferrá ndiz, $2001)^{12}$. Este útero insaciable, "hay tres cosas ins aciables y cuatro que no dicen ¡basta!: El abismo, el vientre estéril, la tierra que no se harta de agua y el fuego que no dice basta" (Prov., Salom ón VII, numéricos), se r edimía con la fecundación y la maternidad, que tornaba la sangre menstrual en el principi o material donde se desarrollaba el movimiento y el alma contenidos en el semen (Ferrándiz, 2001:107). Su retención en mujeres fértiles producía violentos ataques de histeria (Bauhini, 1614), y tornaba a la menopaúsica en venenosa para sí misma y para los demás, pues la sangre pútrida y fétida aquejaba a la mujer de múltiples males psíquicos y físicos (Canet, 1996).

La proyección de la filos ofía cristiana transmutará la impureza en pecado, y la

\footnotetext{
${ }^{11}$ Necesitada de mucho calor innato y sequedad.

${ }^{12}$ Durante la primera cocción el alimento se transforma en quilo en el tubo digestivo, en la segunda el quilo lo hace e $n$ sangre en el hígado animándose con los e spíritus naturales. En la tercera la sangre se distribuye por todas las partes del cuerpo para hacerse carne, por el corazón para infundirse del pne uma vital y por e 1 cerebro para hacerlo del pneuma psíquico. Los testículos convierten esta sangre en esperma en la cuarta cocción.
} 
mujer en su perverso y carnalmente pecaminoso continente (Canet, 1996). Bi ología y mito se fusionan. Fenotípicamente se irá de limitando la maléfica infeliz co mo un ser ambiguo, infértil y viriloide (Libis, 2001). La infertilidad derivará del alejamiento del ideal femenino, pues hablamos de una m ujer "enjuta y seca, avisa da y áspera, de voz gruesa y abultada, verdinegra o $\mathrm{m}$ orena, de pocas carnes, con mucho vello y un poco de barba" (Huarte de San Juan, 19 53:496) ${ }^{13}$. En este ser acédico y terrenal la bilis negra formada en el hígado salía a través de los ojos (Burton, 1621). Las implicaciones de esta teoría en la m utación de la m enopaúsica infértil y virilizada en arquetipos de hechicera andrógina y venenoso (mal de ojo) ya han sido estudi adas con anterioridad (Melián, 2011). En el sigl o XII Hildegarda Bon Bingen, quien at ribuía el origen de la melancolía -nefasta si se ligaba a inestabilidad psíquica- a la caída de Adán, describía a esta fémina como de com ún infértil, complexión mediana, piel amarillenta, carácter inmaduro, irritable y difícil trato con los hombres (Andrés, 2003).

Progresivamente las facultades mágicas y adivinatorias asociadas a sacerdotisas, chamanes femeninos o sabias ancianas se demonizan en un paradigmático modelo de la contaminación de lo creencial sobre lo empírico. Entre los argumentos inquisit oriales del famoso Malleus Maleficarum (Martillo de los Brujos) predominaron manifestaciones de los males del espíritu, donde se fundían la relación funcional entre histeria, melancolía y sexualidad esta blecida por Hipócrates con la identificación mujer/depravación del cristianism o (Kramer, 2006). La procesada era presa de la acedia - pecado capital para Aquino (Peretó, 2010)- o, alternativamente, de una histeria entendida como posesión demoniaca (André, 2008:154). En definitiva, ambas manifestaciones derivaban de un común alejamiento del "bien divino", que Tomás de Aquino definía co mo "tristeza que apesadumbra" en el ca so de la a cedia y como "divagación de la mente por lo ilícito" en las formas de huir de ella (Echeverria, 2004),

"Que, por estar asentada en el castillo del al ma deseando derramarse sin concierto por lo más diverso se la "im portunidad mental". En cuant o pertenece al conocim iento se llama "curiosidad", en cuanto al hablar se llama "verbosidad", en cuanto afecta al cuerpo sin d ejarlo parar en lugar alguno se llam a "inquietud corporal"; cuando po $\mathrm{r}$ ejemplo alguien manifiesta su di vagación mental a través de los desordenados movimientos de su cuerpo, en cuanto lo mueve por diversos lug ares, se llama "inestabilidad (que también puede to marse en el senti do de la volubilidad de propósito" Tomás de Aquino

Muchas procesadas sufrieron una penitencia leve y ejemplarizante, considerando las culpas "cosas de m ujeres" (Melián, 2013b), mientras otras climatéricas y ancianas de "lengua frágil, debilidad de mente y cuerpo, falta de disciplina y memoria,

\footnotetext{
${ }^{13}$ Los hombres temperamento melancólico tenían "color de piel verdinegro o cenizoso, ojos muy encendido; por los cuales se dijo es hombre que tienen mucha sangre en el ojo; el cabello negro y calvos, las carnes pocas, ásperas y llenas de vello con las venas muy anchas (Huarte de San Juan, 1953:459).
} 
credulidad y vanidad" (Kramer, 2006:114) ${ }^{14}$, corrieron peor suerte. Pero unas y otras fueron víctimas de una religión androc éntrica que destiló en su provecho ancestrales alegorías cosmológicas, tan primarias como la naturaleza cíclica, femenina, inestable y enajenada de la luna (Briffaut, 1959).

Para Huarte de San Juan manía y melancolía eran pasiones calientes del cerebro, compartiendo una naturaleza mudable y camaleónica (Huarte de San Juan, 1953: 437). Nuestra desdichada, "asida de la im aginación, avisada, áspera, irritable, de trato difícil", se a semejaba también en es píritu al hom bre melancólico, quien "como la melancolía se enciende y se enfría viven en continua lucha y contienda, sin tener quietud ni sosiego" (Huarte de San Ju an, 1953: 459 y 493) ${ }^{15}$. Pero, m ientras en el varón el brillo de espíritu melancólico fomentará su idealización ligada al genio de inspiración divina durante el renaci miento, y su posterior sublimación asociada a la "belleza del sufrimiento" durante e 1 romanticismo (Galindo, 2005), la mujer permanecerá en la morada de los arquetipos psicológicos negativos.

En pleno siglo XX, Jung asociaba los cu atro elementos básicos con cuatro personalidades: sensual, intelectual, sensitiva e intuiti va (Jung, 1962). El psicoanalista identificaba la personalidad sensitiva a la bilis negra, el carácter melancólico, el otoño, la tierra, la edad adulta y Saturno. Una descripción "iluminada" de la cli matérica, y llamativamente deudora tanto de atáv icos ritos có smicos y mitológicos, como de seculares residuos históricos subyacentes en la génesis de los arquetipos del imaginario humano ${ }^{16}$.

\section{EL MUNDO EMPÍRICO. HISTERIA, MELANCOLÍA, PSIQUIS Y ÚTERO}

El advenimiento de la medicina científica amparó la idea del poder del útero sobre el estado anímico femenino ${ }^{17}$, acreditando la rúbrica sociocultural sobre la homeostasis inconsciente biológica (Damasio, 2003). Desde Charcot y sus zonas histerógenas hasta

\footnotetext{
${ }^{14}$ Estas mujeres actuaban "primero, arrastrando al hombre a un a pasión sin freno, segundo, obstruyendo el poder de gestación; tercero, eliminando los miembros destinados a es e acto; cuarto, convirtiendo a los hombres en bestias por mediación de sus artes, quinto, minando las fuerzas de gestación de las mujeres; sexto, ocasionando el aborto; séptimo, ofreciendo los niños a los demonios, aparte de otros animales y frutos de la tierra en los que se sirven para causar infinitas maldades" (Kramer, 2006:124)

${ }^{15}$ Según Huarte de San Juan la melancolía hace al hombre muy sabio, mal predicador, de poca memoria y buen entendimiento.

${ }^{16}$ El imaginario es definido por Durand como el conjunto de las imágenes y las relaciones de imágenes que constituye el capital pensante del Homo sapiens (Durand, 2005:21)

${ }^{17}$ Ejemplo de e llo son las teorías de la delincuencia -em barazo, el climaterio y el periodo menstrual afectan la im putabilidad de la mujer-, de las $\mathrm{p}$ ersonalidades hormonales, o lo $\mathrm{s}$ propios libros de Marañón en nuestro país sobre la tristeza sexual y las alteraciones patológicas de la psiquis climatérica.
} 
Freud, para el cual melancolía y manía estaban ligadas al papel pasivo de la feminidad y a la represión dada a la vida sexual femenina en la sociedad (André, 2 008). En 1895 el vienés describe la pres encia de la $\mathrm{h}$ isteria en la melancolía y viceversa, pudiendo evolucionar una hacia otra, dado que ambas representan fondos de represión y reacciones emocionales depresivas expresadas corporalmente (Freud, 1996). En ambos cuadros la dependencia psíquica de la mujer al amor del objeto -sin sentir am or como sujeto- condena con el paso de los años a la insatisfacción psíquica y a una hipersensibilidad a las faltas de "consideración" del objeto (André, 2008:198). Freud habla de neu rosis mixtas ${ }^{18}$, como espectros de un c uadro en que la melancolía se caracteriza por la nostalgia sobre un objeto perdido no determinado, mientras que en la histeria se expresa corporal mente manteniendo la investidura del objeto $\mathrm{c}$ on unas consecuencias más visibles y menos devoradoras (André, 2008:199). Atribuy e la predisposición de la posmenopáusica a est a patología a u na libido que reprime intencionadamente, por no estar conforme a la imagen condicionada por la cultura para esa edad (Freud, 1996).

Las teorías actuales definen la emoción como el conjunto de cambios que ocurren en el cuerpo producidos por determinado contenido mental. La percepción cerebral de estos cambios corporales derivados de est ímulos internos o externos activa las glándulas endocrinas y regiones concretas de corteza que se asocian a acciones, expresiones y manifestaciones específicas, afectando secundariamente los sistemas respiratorio, motor y circulatorio (Damasi o, 2010). Esta respuesta "visceral" nos retrotrae a la producción hepática y circulación de la bilis ne gra de los griegos (Eknoyan, 2004) ${ }^{19}$. En su esencia íntima, fluidos, humores, espíritus animales o arreglos valvulares se ha $\mathrm{n}$ trocado e $\mathrm{n}$ cambios moleculares, impulsos nerviosos,

${ }^{18}$ En concreto de la melancólica-histérica, en su obra Estudio sobre la Histeria de 1895.

${ }^{19}$ Desde la endocrinología antropológica encontramos dos grandes corrientes que en el siglo XIX convergerán en el c oncepto de secreciones internas en general y de las gónadas en particular: 1, la teoría humoral y 2, la organoterapia. La primera, formulada por los griegos en los siglo VI y V A.C para jugos y fluidos corporales, fue pe rfeccionada posteriormente por Galeno. Sobre la ba se de una especie de simpatía cósmica del origen divino creador del universo y el cuerpo humano, Galeno transformará los 4 elementos socráticos, tierra, agu a, fuego y aire, en los 4 humores corporales bilis negra, flema, bilis amarilla y san gre, que determinan a su vez 4 caracteres frio, caliente, seco y húmedo. Esta teoría dominará el mundo médico hasta el Renacimiento y, tras el florecimiento de la misteriosa "fuerza vital" del siglo XVIII dará paso a un nuevo sistema en el que la sangre, más que los humores, aparece como el mensajero químico que regula e inte gra las func iones corporales. El humoralismo convivirá durante siglos con la organoterapia, derivada de las ideas totémicas de que cada órgano tiene virtudes particulares transferidas a quien lo consume. Practicado por los egipcios, en Occidente la organoterapia fue practicada por Hipócrates, detallada por Plinio y esqu ematizada por Dioscórides y Galeno. A partir del XIX ambas teorías se fusionan emergiendo el concepto de secreciones internas u hormonas sustituyendo a la sang re, los humores o el jugo, y los órganos quedan sustituidos por glándulas. El cam ino para comprender la "feminidad" desde un punto de vista biológico inicia su veloz andadura hasta la actualidad. 
hormonas y conexiones sinápticas (López- Muñoz, 2011) ${ }^{20}$.

Frente al automatismo de la emoción, el sentimiento resulta de la percepción de lo que nuestro cuerpo hace mientras se manifiesta la emoción y del estado de nuestra mente durante ese periodo de tiem po (Damasio, 2010:176). Com o resultado de la racionalización de una emoción, en ellos in fluyen el enjuicia miento cultural, la conceptualización y percepción de las emociones (Xoro Llacer, 2007). En esta cascada a las e mociones básicas se enumeran como alegría, tristeza, miedo, ira y asco. Del exceso de alegría derivan los sentimientos de euforia y éxtasis, del exceso de tristeza la melancolía y la nostalgia, y del exceso de miedo el pánico y la ti midez (Damasio, 2010). Y de su presentación obsesiva pueden derivar enfermedades psicológicas.

Retornando a la menopausia como brecha en esta medida de eterno retorno que es la fertilidad, las respuestas fem eninas a la cr isis de la m ediana edad no deja $\mathrm{n}$ de ser manifestación de los recursos universales para buscar sentido a la futilidad de la propia existencia $^{21}$. Como consecuencia de las fluctuaciones horm onales y fenómenos vasomotores asociados, ciertos subgrupos de mujeres predispuestas pueden pr esentar una mayor vulnerabilidad a las turbulencias psicológicas y el estrés vital que suelen concurrir temporalmente con esta signifi cativa transición (Brown, 2009; Henderson y cols., 2013) ${ }^{22}$. En la sociedad occidental adem ás "entramos en la etapa menopáusica alejadas de 1 os cánones de belleza, fecundidad y erotismo de 1 a juventud, $\mathrm{s}$ in ser socialmente válidas para reflejar los cánones de sabiduría, equi dad y serenidad, que tienen su iconología en la vejez" (M elián, 2011). Llámese humor, tótem, jugo, sangre, hormona o neurotransm isor, el resultado clín ico es una "hipersensibilidad es piritual" favorecedora, junto a una gran mayoría de respuestas e mocionales adaptativas normales, de una minoría de disfunciones psíquicas. En este contexto de bajo "umbral de vulnerabilidad", la mayor fragilidad de la climatérica frente a estos condicionantes culturales tóxicos puede incidir negativamente sobre los arquetipos contem poráneos comunes de respuesta al climaterio: aventurera, amante, líder, buscadora espiritual, la

20 Para Descartes -en su fam oso Tratado de las Pasiones del Alma de 1649- 1 as pasiones (sentimientos y e mociones) eran movimientos sensitivos del alma (res cogitans) debidos a su unión con el cuerpo (res extensa), un alma localizada en la pineal que desde armonizaba las funciones de la maquinaria humana controlando sus disfunciones por espíritus animales circulantes. La tristeza, com o una de la $\mathrm{s}$ seis pasi ones primitivas del al ma derivaría en melancolía si no se le ponía remedio.

${ }^{21}$ Para Heidegger la ansiedad difiere del miedo en que el segundo tiene un objeto concreto de referencia mientras la primera carece de él. Para combatir esta ansiedad por el sin sentido de la vida en un universo infinito y ciego, Aho enumera la búsqueda de la salvación mediante varias neurosis sociales contemporáneas bien ajustadas: 1, la religión, 2, el acúmulo riqueza 3, la familia, 4, cr uzadas salvadoras o 5, aislamiento de personas contaminadas y/o pecadora mediante meditación, yoga y técnicas similares (Aho, 2008:130).

${ }^{22}$ Fallecimiento de los padres, alejamiento de los hijos y pérdida de la "cotización" para el otro sexo son algunos de ellos. 
jardinera y artista (Shellenbarger, 2005) ${ }^{23}$. Una euforia descontrolada puede conducir a la manía en la aventurera, la a mante y la líder, o al éxtasis en la buscadora espiritual, y una tristeza descontrolada puede conducir a la melancolía o nostalgia en la jardi nera o la artista.

\section{CONCLUSION}

Heredera de un acercamiento mágico y astral al ci clo gonadal femenino, la mujer ha sido etiquetada universal y ancestralmente como inferior, y su naturaleza como perversa, dañina, y psíquicamente inestable. El cese de la fertilidad, único vale dor de dicha naturaleza, y el alejamiento fenotípico de los moldes de perfección y be lleza de la juventud han coope rado secularmente con estas cr eencias primitivas en la transmutación de la $\mathrm{m}$ ujer menopaúsica en enferma del espíritu y/o hechicera. La impronta de estas supersticiones milenarias sobre la construcción de la vi da sexual femenina, y específica mente, del climat erio, definido hoy como "los cam bios biológicos, psicológicos y socioculturales asociados a la in volución gonadal" 24 (Hunter, 2007), es atribuible a la coex istencia hasta el pasado siglo de u na limitada esperanza de vida que lo unificaba con la ancianidad, y el desconocimiento empírico de la íntima fisiopatología gonadal.

\section{REFERENCIAS BIBLIOGRÁFICAS}

AHO, JAMES, AHO, KE VIN (2008): Body Matters. United Kingdom, Lexington books.

ANDRÉ, JACQUES, LANOUZIERE, JAQUELINE, RICHARD, FRANCOIS (2008): Problemática De La Histeria. Madrid, Síntesis.

ANDRÉS, RAMÓN (2003): De la melancolía y la mors voluntarialñ

Humanitas, Humanidades médicas 4, 329-336.

AYERS, BEBERLY y cols (2010): The impact of attitudes towars the m enopause on women's symptom experience: a systematic review. Maturitas 65: 28-36.

BAUHINI, CASPARI (1 614): De Hermaphroditorum natura. Basilea, Theodori de Bry.

BRIFFAULT, ROBERT (1959): The mothers. London, Ruskin House.

23 Estos arquetipos son fácilmente deducibles, salvo quizás la jardinera, que encuentra el equilibrio sublimando sus relaciones en el pequeño mundo que tiene a su alrededor en lugar de iniciar rupturas traumáticas, como ocurre en los otros. 
BROMBERGER, JOYCE (2011): "Mood and menopause: findings from the study of women's health across the nation (SWAN) over 10 years Obstet Gynecol Clin N Am 38, 609-625. BROWN, JESSICA y cols (2 009): "Relations among m enopausal symptoms, sleep disturbances and depr essive symptoms in the midlife". Maturitas 62,184-189.

BURTON, ROBERT (2006): Anatomía de la melancolía. Madrid, Alianza editorial.

BYNUM, BILL (2001a): Discarded diagnoses: Acedia The Lancet 357, 1985.

BYNUM, BILL (2001b): Discarded diagnoses: Nostalgia The Lancet 358, 2.

BYNUM, BILL (2002): Discarded diagnoses: Maternal impressions The Lancet, 898.

BYNUM, BILL (2003): Discarded diagnoses: Ectasy The Lancet 362, 1863.

CANET, JOSÉ LUIS (1996): "La mujer venenosa en la época medieval".

http://parnaseo.uv.es/Lemir/Revista1/Mujer_venenosa.html

CIRLOT (2003): Diccionario se símbolos. Madrid, ed. Ciruela.

DAMASIO, ANTONIO (2003): Looking for Spinoza. Londres, Vintage books.

DAMASIO, ANTONIO (2010): Y el cerebro creó al hombre. Barcelona, Destino.

DURAND, GILBERT (2005): Las estructuras antropológicas del imaginario. Méjico, Fondo de Cultura Económica.

ECHEVERRÍA, MAURICIO (2000): La acedia y el bien del hombre en Santo Tomás" e-aquinas 2, 13-34.

ECKNOYAN, GARABED (2004): E mergence of the concept of endocrine function and endocrinology Advances in Chronic kidney disease 11:371-376

EISSLER, ROBERT (1946): The royal art of astrology. London, Herberth Joseph Ltd.

FERRÁNDIZ, CARLOS (2001): Dioscórides (Bestiario) de A. Laguna. Madrid, Medusa.

FRAZER, JONATHAN (1951): La Rama Dorada. Magia y Religión. México, Fondo de Cultura Económica.

FREEMAN, ELLEN (2010): Associations of de pression with the transition to menopause Menopause 17, 823-827.

FREUD, SIGMUND (1917): Duelo y melancolía.

Disponible en: www.aldevara.es/download/DueloYMelancolia_SigmundFreud.pdf

FREUD, SIGMUND (1996): Estudios sobre la histeria. Obras completas, I. Madrid, Biblioteca Nueva.

GALINDO, GABRIELA (2005) : Ocho pasos para entender la Melancolía Réplica 21: Disponible

en: http://replica21.com/archivo/articulos/g h/385 galindo melancolia.html 
HENDERSON, VICTOR y cols $(2$ 013): Cognition, mood and physiological concentrations of sex horm ones in the early and late postm enopause Procedings National Academy of Science 110: 20950-20955/04/2014)

HUARTE DE SAN JUAN (1953): Examen de los Ingenios. Biblioteca de Autores Españoles, XLV. Madrid, Atlas.

HUNTER, MYRA (2007): Bio-psycho-socio-cultural perspectives on menopause.aBest practice \& Research Cinical Obstetrical and Gynecology 21, 261-274.

IGLESIAS-BENAVIDES, JOSÉ L UIS (2009): La menstruación: un asunto sobre la luna, venenos y flores Medicina Universitaria 11, 279-287.

JUDD, FIONA (2012): Depression and midlif e:are we overpathologising menopause? Journal of affective disorders 136, 199-211.

JUNG CARL (1962): Símbolos de transformación. Buenos Aires, Paidós.

KRAMER, HEINRICH, SPRENGER, JACOBUS (2006): Malleus maleficarum. El martillo de los brujos. Barcelona, Círculo Latino.

LIBIS, JEAN (2001): El mito del andrógino. Madrid, Siruela.

LLANEZA, PLÁCIDO y cols (2011) : Depressive disorders and the $\mathrm{m}$ enopause transition Maturitas 721, 120-130.

LÓPEZ-MUÑOZ, FRANCISCO y cols (2011): Sadness as a passion of the soul: a physiopathological consideration of $t$ he cartesian concept of melancholy Brain Research Bulletin 85, 42-53.

MARTÍNEZ HERNÁNDEZ, ANGEL (2011): Antropología médica. Teorías sobre la cultura, el poder y la enfermedad. Madrid, Anthropos.

MELIÁN, ELVIRA (2011): En la b arca de Caronte (la m enopausia o la gran transformación) Feminismo/s 18,185-202

MELIAN, ELVIRA (2013-a: La ex periencia mística durante el clim aterio: un acercamiento desde la endocrinol ogía antropológica Investigaciones Feministas 4,323-334.

MELIAN, ELVIRA (2013b): Antes de Francis ca:La beata Isabel Bautista de San Jerónimo o el origen de un proyecto reformista segado por la inquisición Tole dana en el siglo XVI Estudios Humanísticos. Historia 12, 91-104.

MENG, HEINRICH y cols (1920): Endocrinología psicosomática (psique y hormonas). Madrid, Morata.

NEUMAN, ERICH (2009): La gran madre. Una fenomenología de las creaciones femeninas de lo inconsciente. Madrid, Trotta.

PERETÓ RIVAS, RUBÉN (2010): El itinerario medieval de la acedia Intus-Legere Historia 4, 33-48.

SHELLENBARGER, SUE (2005): The breaking Point. New York, Owl Books. 
SULLIVAN, ERIN (2008): The art of medicine. Melancholy, medicine, and the arts The Lancet 13, 884-885.

WEBER, MIRIAN y cols (2014): Cognition and mood in perimenopause: a systematic review and meta-analysis Journal of Steroid and Biochemistry and Molecular Biology 142, 90-98.

WEIDEGER, PAULA (1976): Menstruation and menopause: the physiology and psychology, the myth and reality. New York, Random House.

XORO LLACER, XAVIER (2007): De la Melancolía en las artes plásticas de Occidente. Valencia, Universitat Politécnica de Valencia.

ZAFON, CARLES (2012) E ndocrinología evolutiva: una asignatura pendiente Endocrinol Nutr 59, 62-68. 